\title{
AC 2007-2724: DEVELOPING HIGHER ORDER PROBLEM SOLVING SKILLS THROUGH PROBLEM-BASED LEARNING (PBL) IN A MANUFACTURING PROCESS ENGINEERING COURSE
}

\section{Danny Bee, University of Wisconsin-Stout}

DANNY J. BEE is an Assistant Professor of Manufacturing Engineering since 1995 and the former Program Director for Manufacturing Engineering at the University of Wisconsin-Stout. He earned a B.S. in Mechanical Engineering at the University of Wisconsin-Madison and a M.S. in Manufacturing Systems Engineering at the University of Wisconsin-Madison. He has design/manufacturing experience in the aerospace and computer industries. In addition, he worked as a Quality Specialist in the Janesville/Beloit, WI region at Blackhawk Technical College. He is currently a Ph.D. student in mechanical engineering at Michigan Technological University, developing research in the area of environmentally responsible design and manufacturing.

\section{Bob Meyer, University of Wisconsin-Stout}

BOB MEYER is the Dean of the College of Technology, Engineering, and Management (CTEM), University of Wisconsin-Stout. He has a B.S. in Industrial Education (UW-Stout), M.S. in Manufacturing Management (UW-Stout), Ph.D. in Industrial Engineering (U of Minnesota). His previous experience includes CTEM Associate Dean of Outreach at UW-Stout; Stout Technology Transfer Institute Director (STTI); Northwest Wisconsin Manufacturing Outreach Center Director (NWMOC) a NIST/MEP affiliated center; Advanced Design and Manufacturing Simulation Center Director, UW-Stout; Manufacturing Engineering Program Director, UW-Stout; General Machinist, Johnson Brass and Foundry; General Machinist, Badger Dynamics. 


\title{
Developing Higher Order Problem Solving Skills through Problem-based Learning (PBL) in a Manufacturing Process Engineering Course
}

\begin{abstract}
A program revision to the Bachelor of Science in Manufacturing Engineering program at the University of Wisconsin-Stout created a series of new courses titled "Manufacturing Process Engineering I and II." This provided an ideal subject matter to implement a problem-based learning (PBL) approach for in-depth manufacturing process engineering topics. During the Fall 2006 semester, the junior level Manufacturing Process Engineering I (MFGE-351) course was taught utilizing a facilitated problem-based learning methodology. The early results from this change in teaching method indicates that 1) students greatly appreciate the opportunity to apply theoretical content of an engineering science course to real world problems and situations they will face, 2) students researched the problems to a greater depth than in a typical lecture/lab based class, and 3) the level of enthusiasm for learning the engineering science topics is greatly increased. To properly assess learning achievement in a PBL curriculum, genuine situational assessments will be implemented along with the change in instructional technique. This paper describes the PBL approach and assessment methods used in this new course and summarizes student perceptions of their experience with the PBL methodology within the course. In addition, both the instructor and student perceptions of the shift from lecture-based to a facilitative instructional method will be discussed.
\end{abstract}

\section{Course Overview}

The first offering of the Manufacturing Process Engineering I course was Fall 2005. This offering was taught in a traditional lecture based manner. The latest offering of the course in Fall 2006, utilized a problem-based learning approach. It is important to understand each of the two methods of teaching the course.

\section{Previous Offering}

In the Fall of 2005, the first time offering of the Manufacturing Process Engineering I course was taught in a traditional lecture based manner. The course included the application of finite element analysis (FEA) utilizing Microsoft Excel. Individual modeling assignments took extensive amounts of time and were applied to the modeling of chip-tool interface temperatures in a machining operation and modeling the forces and pressures in metal forming processes such as forging and rolling. ${ }^{1}$ In addition, multiple text book assignments were utilized, a 3-D solid modeling project was created, one published research issue was researched and documented, and an open-ended team project was performed.

The individual modeling assignments were time intensive due to the need to elevate each student's knowledge of and use of MS Excel for FEA modeling. Even though the students were juniors in the manufacturing engineering curriculum and all were part of the university-wide laptop lease program, their understanding and knowledge of Excel was not high enough to simply turn the students loose with it after brief demonstrations on how to do the modeling. 
Each of the three modeling assignments took a minimum of $2 \frac{1}{2}$ weeks of instruction to ensure most students had completed them.

Traditional textbook homework sets were used to introduce the concepts utilized in the FEA modeling. The instruction for these materials was first introduced in a traditional lecture format and the outlines closely followed the topic material in the text.

A 3-D solid modeling project was performed utilizing UGS IDEAS software. While a very powerful modeling software, the project was first introduced with the requirement that all students must demonstrate solid modeling proficiency on the software. If students did not have this proficiency from previous experience or instruction, a basic modeling lesson was taught and then students were instructed to follow the online tutorials available in the software. Once students were able to demonstrate their modeling proficiency, a complicated sheet-metal part drawing was provided, and they were required to submit a completed model of the part utilizing the sheet metal tools within the software.

Students in MFGE-351 were asked to utilize published research on the topic of quick change tooling or single-minute exchange of dies. The use of library available, database search tools was expected. In addition, students were asked to locate online web-based resources and accurately evaluate these for content validity and application usefulness. While a fairly successful project, it only proves that students can find an article of interest or a website of interest fairly easily. It also proves that students can find key points of information and regurgitate that information back into a report.

The final course activity was a precursor to the improved open-ended problem based approach. The topic of "Industrial Ecology" or "Sustainability" was introduced in the context of a product suddenly being forced to comply with European Union (EU) Product Take-Back Directives. Student teams developed a method for solving the issue of dealing with implementation of these types of directives in the context of a product of their choosing. Products ranged from bicycles, incandescent light bulbs, furniture, and electronic pizza rotisseries. Students presented some basic projects without much depth for implementing the compliance to the directives with their products. While a great discussion tool for this sorely needed topic within an engineering program, it was obvious, from the lack of depth in the product implementation plans, the students were not comfortable with researching a topic and making detailed decisions and developing meaningful assumptions for all issues related to the implementation of these EU Directives.

As the instructor for this course, I felt the lecture and project based approach was not developing the engineering problem solving skills deemed important by the manufacturing engineering program outcomes. Students did not appear motivated by this courses methods, assignments, and projects.

\section{Current Offering}

During the Fall 2006 semester, a new approach to teaching the Manufacturing Process Engineering I course was implemented. The new course design broke the class into four teams, each having four members. Open-ended, real, engineering problems were given to the teams. The teams were required to develop a solution to the problems. Throughout the team solving 
time, I functioned as a facilitator of the problem-based method, asking them probing questions into their problem solving approach, on their information located from research, and on the validity of their resources utilized. This facilitative approach mirrors the basic problem-based learning (PBL) methods developed by Barrows ${ }^{2}$ and the McMaster University engineering programs. ${ }^{3}$. In addition to three PBL problems, the students individually completed a sheet metal design project utilizing newly implemented Solidworks CAD software and one MS Excel based FEA solution to cutting tool temperature distribution. This individual FEA assignment, much of it lecture based in instruction, was included to allow the students a direct comparison base to contrast the two methods. This reflective assessment was collected anonymously at the end of the semester utilizing the online course management information platform.

\section{Problem-based Learning Application}

Utilizing a problem-based learning methodology requires a complete change in instructional style. First, the instructor must realize that the PBL method of instruction requires a facilitative approach. This interactive approach requires posing a problem, helping the teams identify what knowledge is required to solve the problem by probing their thinking processes, and creating a reflective environment on whether the knowledge gained was useful and the validity of the resources used ${ }^{4,5}$. Barrows ${ }^{6}$ outlines six key aspects of problem-based learning:

- Learning is student-centered.

- Learning occurs in small student groups.

- Teachers are facilitators or guides.

- Problems are the organizing focus and stimulus for learning.

- Problems are the vehicle for the development of clinical problem-solving skills.

- New information is acquired through self-directed learning.

Borrowing from personal instruction received from Southern Illinois University by Howard Barrows and associates and the many readings that summarize a PBL implementation within undergraduate learning, the Manufacturing Process Engineering I course curriculum was improved with PBL.

\section{Descriptions of Open-ended Problem Used}

The first course PBL problem was a realistic problem dealing with the development of a tooling design system and was stated as follows:

"As the newly hired Tooling Engineer, you have the responsibility to design, fabricate, and release to the manufacturing facility all new tooling required to machine and/or metal form products your company manufactures. This tooling needs to maintain our company focus on single minute exchange of dies as well as handle all process forces and temperatures. This problem will only deal with new product tooling requirements."

As seen in this statement, the scope of the project is limited to a tooling design application. However, the problem is broad in nature and does not have a clear definition or solution. In other words, it is messy, just like a real-life engineering problem. In addition to the problem statement, the following "Problem Deliverable" was outlined: 
"Completion of this project will be based on the development of a tooling design system/philosophy that successfully encompasses all process issues that need to be dealt with from the processes of metal forming and machining while also maintaining the company focus on single minute exchange of dies. This report will be presented to your coworkers and management for implementation and acceptance. The final report must detail this system, along with complete definition of all issues identified and investigated during the project work. Group member reflections on the process will also need to be included as part of the final work requirements for this project. Note: These reflection statements will be done via the Learn@UW-Stout course site."

The student teams immediately identified they would need to know all of the types of equipment related to machining and metal forming present in the manufacturing company for which they were "working." This was expected and a known local mid-sized manufacturer's capabilities, as defined by they advertisements on their website was provided. Teams then have to work identifying what information they would need to be able to create this tooling design system. As the facilitator of this process, I observed the teams working and asked them questions of what was the information behind a suggested system design point. While the team was brainstorming their ideas and solutions, these "outsider" questions required them to step back into their own thought processes and assess what was the technical information that 1) created the idea and 2) what additional information would be required to ensure the team completely understands the idea or implementation. By questioning their knowledge and helping the teams identify their knowledge gaps, the teams were then able to identify what additional information they needed to obtain. Once the individual members of the team had gone out, done their research, and presented it back to their fellow team members, I again questioned them on the validity of the information obtained and the usefulness of the resources utilized.

Periodically, approximately once per week, each team reported to the entire class and provided an update on their current solution to the problem. These report out sessions were interactive with all groups participating and learning about the directions and learning issues identified in the other groups. In addition to the weekly group report out sessions, class members completed weekly individual reflection statements. The reflection questionnaires asked the following questions:

1. Describe how you are contributing to the success of your team's problem investigation and solution.

2. Describe how other members of the group are contributing to the investigation and solution of the problem.

3. What do you feel is working well with this problem based learning process?

4. What improvements do you suggest for this problem based learning approach?

The responses to the reflective questions were collectively summarized in an anonymous format. I read these at the completion of the week and adjusted the process as the projects progressed.

The second course PBL problem was a realistic problem about developing a progressive die design and was stated as follows: 
"As the Manufacturing Engineer, you have the responsibility to design, fabricate, and release to the manufacturing facility all new tooling required to form products your company produces within your progressive stamping facility. A new part (provided) has been given to your company to produce. The tooling needs to maintain our company focus on single minute exchange of dies. Equipment sizing of needed machine tools will need to be determined. This part came from a prototype production of the part from your customer. They do not have CAD drawings to provide with this. Our internal CAD system is Solidworks and all tooling/part communications is made via Solidworks."

In addition to the problem statement, the following "Problem Deliverable" was outlined:

"Completion of this project will be based on the development of the required solid model and drawings of the part and the associated tooling. A report will be presented to your coworkers and management for implementation and acceptance. The final report must detail all product and tooling designs, addressing all issues identified, understood, and investigated during the project work. Group member reflections on the process will also need to be included as part of the final work requirements for this project. Note: The individual reflection statements will be done via the Learn@UW-Stout course site."

This second PBL problem was assigned and completed after the class had spent some introductory time learning to use Solidworks. While some students had had formal Solidworks use in a Solid Modeling CAD course, others in the class had not. Large class demonstration and instruction on the use of the software took place and students completed the online tutorials on their own if they needed to increase their familiarity with the software. Each individual student also completed a sheet metal solid modeling project to demonstrate proficiency with the software. There was an additional individual project based problem.

The PBL process followed for this project was the same as PBL problem 1. A course lecture on the details of progressive die design was added when all teams identified a need to learn about progressive die design in more detail. By the completion of this project, the group report at the end was an extremely interactive learning experience for all members of the class. Comments were very constructive for how other teams could change or implement other team's ideas. Time was given for the teams to revise their final project deliverable with this feedback from the class discussions.

The final course PBL problem was a realistic problem about industrial ecology or environmentally responsible design and manufacturing and was stated as follows:

"The company you work for is aware of a newly passed regulation that will mandate the product you make must have zero environmental impacts at the end of its useful life by the year 2008. All new products sold after this date will be returned to you and you will be responsible for handling them. You are a project team responsible for implementing this and have the necessary team membership, e.g., manufacturing engineer, procurement engineer, traffic engineer, design engineer, to do whatever is needed. You also have top management's support to do whatever is needed to maintain our product market.

- How would you go about implementing this?

- What information do you need? 
- What resources will you use to find this information?

Since this unit is an abbreviated one, your group will need to quickly discuss this topic, deciding on four (4) key issues that need to be researched for baseline information (focus on just developing the understanding of the topic for this PBL case). During the Monday and Wednesday classes remaining, each team member should take one of these four issues and thoroughly research it."

In addition to the problem statement, the following "Problem Deliverable" was outlined:

"During the scheduled evaluation week class meeting time:

1. Come prepared to class to discuss the information your team found related to each of your key issues. Be ready to discuss how well the resources you used worked for your team. This will be done in an open discussion format.

2. Submit (electronically) a short written report briefly summarizing (target $1 / 2$ page for each summary) each of the four (4) key issues researched by your team. Please also include a brief discussion pertaining to the quality of the resources the team located, listing them if possible as well."

As can be seen in the above problem description, time was running short, and this problem was abbreviated to reflect the time remaining in the course. Problem resolution and the deliverable were focused on the knowledge need identification, information validity and usefulness, and the validity of the resources utilized.

\section{Descriptions of Individual FEA Modeling}

The remaining activity to summarize in this paper, from the current course curriculum, is the cutting tool temperature FEA modeling. This was an identical assignment, described earlier, to the previous course offering discussion. The reason for performing this assignment was again to allow for a direct comparison of the PBL methodology and a lecture-based subject oriented methodology within the same current course offering. A final cutting temperature reflections survey was conducted for this assignment, using the same anonymous summation format for the open-ended questions.

\section{Results from Change in Teaching Method}

Results from this PBL implementation are very encouraging. Each of the PBL problems, tooling system design, progressive die design, and industrial ecology, were summarized in reflection by the students. Comments are similar to other problem-based learning discussions and references. A few students were not overly appreciative of the PBL method. They stated, "There needed to be more definition of the deliverable required," or "There needed to be more information presented in lecture style up front." The majority of comments were supportive of the PBL process and are best summarized by these statements, "I like the different ways you need to think that are relevant to real world situations," and "I feel that us engineering types learn better with a hands on approach as opposed to reading and chapter questions. That is the greatest advantage of this process." 
As the teams progressed through the semester, there was a change in comments of "needing more information up front," "be more specific in defining the scope of the problem," and "there needs to be a clear definition of the deliverable requirements" at the beginning of the semester. By the end of the semester, as summarized in the final course evaluations, student comments were much more positive. The best summation of the student thoughts on PBL were stated in this reflective statement.

"Being my first experience with Problem Based Learning, I really enjoyed it. As much as I love engineering and all of the topics of study that we are exposed to here at Stout, sometimes-traditional lectures get dry and boring. This new method worked really well in being able to finally get a chance to apply some of what we have learned through lecture in previous classes. It was almost a reminder that we will really be using a lot of this "stuff" we are learning in class. Overall, great experience. Needs some tweaking as far deadlines and schedules go, but I would definitely recommend that you follow the same method for this class next semester."

Another stated the aspect of researching a topic for understanding as follows:

"Overall I liked the PBL. It gave students the opportunity to take direction of their topic. This was nice to be able to think outside the box and research how group members saw fit." Overall, this course implementation of problem-based learning was deemed a success, and this paper has presented the overall framework for how a course was transitioned from a traditional subject based lecture intensive engineering science course to one based on problems presented in the context of real engineering problems.

\section{Bibliography}

1. Tlusty, J., Manufacturing Processes and Equipment, Prentice Hall, Inc., Upper Saddle River, NJ, 2000.

2. Perrenet, J., Bouhuijs, P., and Smits, J., "The Suitability of Problem-Based Learning for Engineering Education: Theory and Practice," Teaching in Higher Education, Vol. 5, No. 3, pp. 345-358, 2000.

3. Woods, D. et. al., "Developing Problem Solving Skills: The McMaster Problem Solving Program," Journal of Engineering Education, Vol. 86, No. 2, pp. 75-91, 1997.

4. Smith, K., Sheppard, S., Johnson, D., and Johnson, R., Pedagogies of Engagement: Classroom-Based Practices, Journal of Engineering Education, Vol. 94, No. 1, pp. 87-101, 2005.

5. Barrows, H. and Tamblyn, R., Problem-Based Learning: An Approach to Medical Education, Springer, New York, NY, 1980.

6. Barrows, H., "Problem-Based Learning in Medicine and Beyond: A Brief Overview," in Wilkerson, L. and GIjeseaers, W., eds., New Directions for Teaching and Learning, No. 68, pp. 3-11, 1996. 